\title{
Spirulina platensis Enhances the Beneficial Effect of Exercise on Oxidative Stress and the Lipid Profile in Rats
}

\author{
Daiane Mazzola ${ }^{1}$, Fernando Fornari $^{2}$, Gabriela Vigano ${ }^{1}$, Tatiana Oro ${ }^{1}$, Jorge Alberto \\ Vieira Costa ${ }^{3}$ and Telma Elita Bertolin ${ }^{1^{\star}}$ \\ ${ }^{1}$ Laboratório de Tecnologia das Fermentações; Instituto de Ciências Biológicas; Universidade de Passo Fundo; \\ Passo Fundo - RS - Brasil. ${ }^{2}$ Faculdade de Medicina; Universidade de Passo Fundo; Passo Fundo - RS - Brasil. \\ ${ }^{3}$ Faculdade de Química e Engenharia de Alimentos; Universidade Federal do Rio Grande;Rio Grande - RS - Brasil.
}

\begin{abstract}
This study aimed to evaluate the effect of Spirulina platensis and moderate exercise on oxidative stress and lipid profiles in the rats. Forty male Wistar rats were allocated to the following 10-week treatments, three times a week: exercise (E, $30 \mathrm{~min}$ swimming), S. platensis (SP, $26 \mathrm{mg} / \mathrm{Kg}$ ); exercise and Spirulina (ES); and control (C). Outcomes were Thiobarbituric Acid Reactive Substances (TBARS) in serum and brain, and cholesterol and triglycerides (TG) in serum. Rats treated with exercise showed lower brain TBARS than the controls, mostly in association with S. platensis. In the groups $E$ and ES, serum TBARS decreased after intervention. Compared with the controls, both $E$ and ES prevented an increase in cholesterol and reduced triglycerides. Results demonstrated that S. platensis enhanced the beneficial effect of exercise on oxidative stress and lipid profiles in rats, which might be a promising approach for treating metabolic syndrome in humans.
\end{abstract}

Key words: Exercise, antioxidant, cholesterol, lipid peroxidation

\section{INTRODUCTION}

The aging process has been considered a major epidemiological phenomenon of humanity, given the impressive increase in life expectancy observed in the last century (Blagosklonny 2010; Vaupel 2010, Scott et al. 2015). Consequently, the search for new preventive and therapeutic strategies has received special attention by the scientific community (Farooq et al. 2014; Quirós et al. 2015). Among several mechanisms involved in the process of aging, oxidative stress and hyperlipidemia have been considered as new targets for therapeutic approaches (Wang and Michaelis 2010; Gamba et al. 2015; Hare et al. 2015) because both participate in the pathogenesis of atherosclerosis and metabolic syndrome
(Ungvari et al. 2010; Onat et al. 2012). According to Vaziri et al. (2010), the available pharmacological therapies have been largely ineffective in ameliorating oxidative stress, inflammation, HDL deficiency and/or dysfunction, atherosclerosis and cardiovascular disease. In this context, there is need to search for new therapeutic strategies.

Several nutritional components have been tested as antioxidant agents, such as vitamins, flavonoids and ubiquinone (Macedo et al. 2014). Recent studies have described an antioxidant effect of $S$. platensis, a cyanobacterium that contains phycocyanin, which in turn acts by promoting inactivation of free radicals (Bermejo-Bescós et al. 2008; Pabon et al. 2012; Farooq et al. 2014). S. platensis has been marketed in many countries

*Author for correspondence: telma@upf.br 
and utilized as nutraceuticals, demonstrating good safety profiles. It has other potential benefits, including anti-inflammatory, hypolipidemic and antineoplastic activity (Zheng et al. 2013; Farooq et al. 2014). Moderate levels of aerobic exercise have also been demonstrated to reduce oxidative strandess (Venditti and Di 1997; Cakir et al. 2010).

Animal and human studies have indicated that moderate exercise induces liberation of Reactive Oxygen Species (ROS), followed by activation of antioxidant enzymes, resulting in a beneficial balance in favor of antioxidant processes (GomezCabrera et al. 2008). However, it is known that extenuating exercise may result in cellular damage due to excess production of ROS (Vina et al. 2000), suggesting that exercise as a therapeutic approach should be used in moderate levels. Thiobarbituric Acid Reactive Species (TBARS) have been used in the analysis of lipid peroxidation by means of malonaldehyde measurement, which is considered a marker of oxidative stress (Babusikova et al. 2007; Sainz et al. 2010). The combination of hyperlipidemia and oxidative stress has been shown to act synergistically in the process of aging (Babusikova et al. 2007; Zhao et al. 2015), particularly in brain damage (Navarro and Boveris 2010) and atherosclerosis development (NegreSalvayre et al. 2010), potentially resulting in a variety of chronic diseases (Adibhatla and Hatcher 2008; Navarro and Boveris 2010). Treatments able to interfere in both oxidative stress and hyperlipidemia would have great relevance in clinical practice. It was hypothesized that a combination of $S$. platensis and moderate exercise could potentiate the benefic effects of exercise on oxidative stress and the lipid profile. Thus, this study aimed to answer this question in the rats.

\section{MATERIAL AND METHODS}

\section{Animals}

A total of 40 male Wistar rats (five months old) were studied. They were categorized in four groups of 10 animals, which were treated for 10 weeks with one of the following interventions: exercise (E); S. platensis (S); exercise and $S$. platensis (ES); and control (C).

\section{Interventions}

The animals received standard rodent chow, balanced according to the recommendations of the
National Research Council and National Institute of Health (USA), the Nuvital make, type Nuvilab CR1. The amount of feed provided was $20 \mathrm{~g} / \mathrm{day}$, average intake of an adult mouse (Fiocruz 1994). The rats were fed early at around $10.00 \mathrm{am}$. The animals were subjected to seven days acclimatization for swimming to receive treatment by gavage (in this period, all the animals received saline by gavage). S. platensis used for the experiments was obtained from the Universidade Federal do Rio Grande, Escola de Química e Alimentos, Laboratório de Engenharia Bioquímica, Rio Grande-RS, Brazil in the form of a powder, which was prepared by drying the microalgal biomass, followed by pulverization in the ball mil, and then maintained at $-20^{\circ} \mathrm{C}$. For aerobic exercise, a pool was designed to allow four animals to swim simultaneously. The experiment was conducted in accordance with Brazilian law 11.794/08 and ethical principles from Brazilian Society of Laboratory Animal Science (SBCAL). The study was approved by the Ethics Committee - Universidade de Passo Fundo (certificate $\mathrm{n}^{\circ} 006 / 2010$ ).

\section{Study protocol}

The steps of the study are presented in Figure 1.

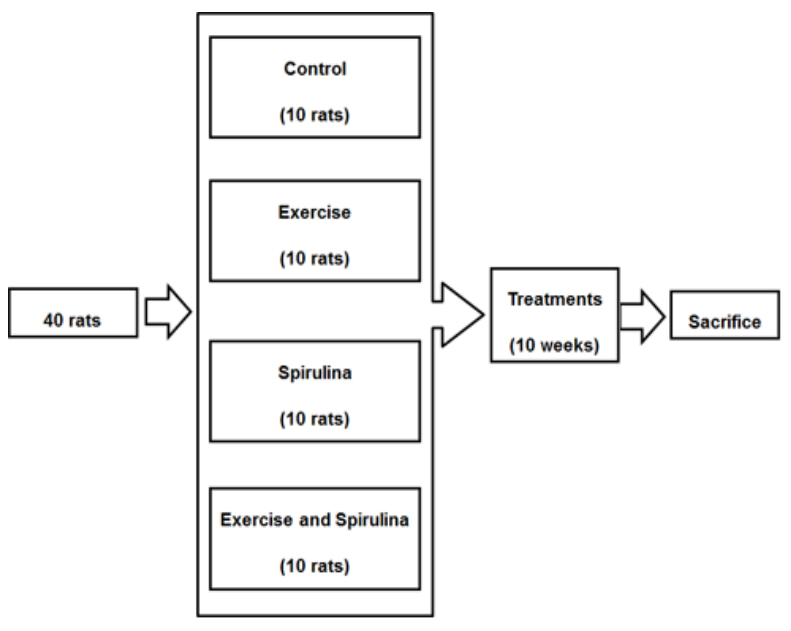

Figure 1 - Experiment flow sheet.

Rats were randomly allocated to one of the four interventions. Rats of group E underwent a $30 \mathrm{~min}$ session of swimming in water at $32^{\circ} \mathrm{C}$ (Fig. 2A), three times a week for ten weeks. They also received oral saline by gavage (Fig. 2B) before exercise. The subgroups $\mathrm{S}$ and ES were treated with $S$. platensis $(26 \mathrm{mg} / \mathrm{kg})$. This quantity was diluted with $2.00 \mathrm{~mL}$ of distilled water and then subjected to the rats for oral gavage three times a 
week. This amount was based on the calculation of National Health Surveillance Agency (ANVISA) data as $1.6 \mathrm{~g} /$ day for an adult human of $60 \mathrm{~kg}$. Subgroup ES underwent all the steps described above, with exception of oral $S$. platensis, instead of saline. Subgroup $C$ received oral saline three times a week. Blood samples were collected from the retro-orbital vein before

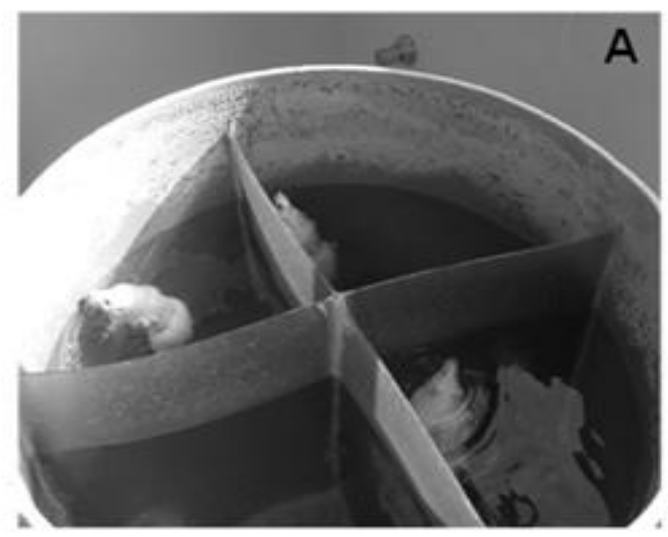

starting the interventions and then 10 weeks later. Rats were weighed once a week during the experiment. Between the interventions, the animals were kept in collective cages with free access to food and water and a 12:12-h light-dark cycle. At the end of the experiment, the animals were sacrificed by guillotine, followed by removal of the brains.

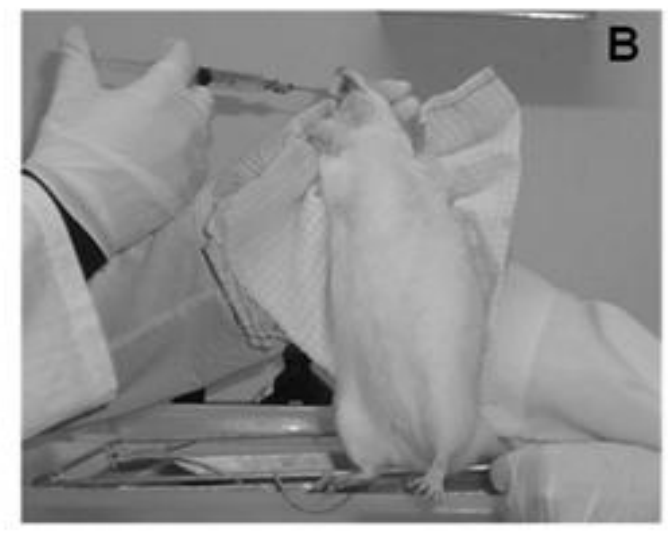

Figure 2 - Experimental procedures. (A) Rats exercising in the specially designed swimming pool. (B) A rat receiving oral saline by gavage.

\section{Thiobarbituric acid reactive substances (TBARS)}

TBARS were analyzed in serum and brain tissue. Blood samples from the pre- and post-treatment measurements were collected in a heparinized tube and were centrifuged at $3000 \mathrm{rpm}$ for $10 \mathrm{~min}$. The supernatant was removed and stored at $-80^{\circ} \mathrm{C}$ in microtube of $2 \mathrm{~mL}$. Brain tissue from the right hemisphere was homogenized with phosphate buffer, $\mathrm{pH}$ 7.4. Determination of TBARS was performed as described elsewhere Steels et al. (1994). TBARS concentration in the serum and brain was determined from the absorbance at 532 $\mathrm{nm}$ and expressed in nmol.

\section{Lipid profile}

Total cholesterol (TC) and triglycerides (TG) were measured in the serum collected before and after the treatment. The analyses were carried out utilizing the commercially available reagent kits (Labtest, Lagoa Santa - Brazil).

\section{Statistical analysis}

Quantitative variables were first tested for Gaussian distribution. Data were expressed as the mean and standard deviation (SD) or when otherwise stated. Student $t$ tests, ANOVA, $\chi^{2}$ test or Fisher's exact test were employed when appropriate. The analysis was performed using GraphPad Prism 5 (GraphPad Software, Inc., San Diego, CA, USA). A P value $<0.05$ was accepted as indicating significance.

\section{RESULTS}

\section{Animals}

Out of 40 rats, three died during the procedures: two from the exercise group and one from the control group. Thus, the final study sample was composed of 37 rats. Weight gain after treatment was significantly higher in both the controls (pre $360 \pm 17 \mathrm{~g}$ vs. post $421 \pm 33 \mathrm{~g} ; \mathrm{P}<0.001$ ) and $\mathrm{S}$ rats $(352 \pm 23$ g vs. $409 \pm 15 \mathrm{~g} ; \mathrm{P}<0.0001)$. The $\mathrm{E}$ $(368 \pm 40 \mathrm{~g}$ vs. $384 \pm 27 \mathrm{~g} ; \mathrm{P}=0.064)$ and $\mathrm{ES}$ groups $(385 \pm 42$ g vs. $409 \pm 43 \mathrm{~g} ; \mathrm{P}=0.064) \mathrm{did}$ not have a significant increase in the weight (Fig. $3 \mathrm{~A})$. Inter-treatment comparison revealed that the magnitude of weight increase was significantly higher in the controls than in both the ES group $(61.0 \pm 20.9$ g vs. $23.6 \pm 30.4 \mathrm{~g} ; \mathrm{P}<0.01)$ and $\mathrm{E}$ group $(61.0 \pm 20.9$ g vs. $16.5 \pm 17.0 \mathrm{~g}$; $\mathrm{P}<0.01)$. The $\mathrm{S}$ group had a significant weight increase when compared with the ES $(56.7 \pm 14.6 \mathrm{~g}$ vs. $23.6 \pm 30.4 \mathrm{~g} ; \mathrm{P}<0.01)$ and $\mathrm{E}$ groups $(56.7 \pm 14.6$ g vs. $16.5 \pm 17.0 \mathrm{~g} ; \mathrm{P}<0.01)$ (Fig. $3 \mathrm{~B})$. 
A

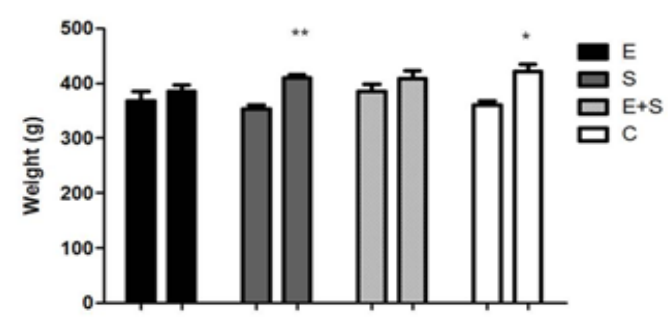

B

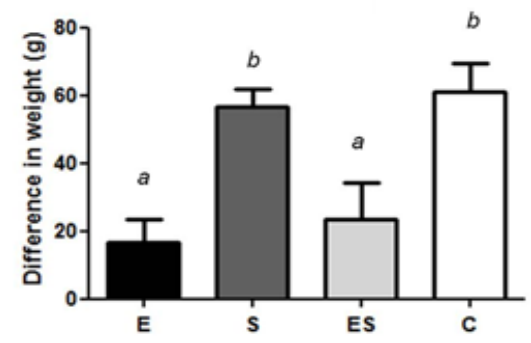

Figure 3 - Exercise and exercise associated with S. platensis prevented the increase in weight. (A) Weight before and after treatments. Data are presented as the mean and std. deviation. $* \mathrm{P}<0.001$; $* * \mathrm{P}$ $<0.0001$ (Student $t$ tests followed by two way ANOVA). (B) Difference in weight after tenweek treatments. Data are presented as the mean and std. deviation. Different letters represent significant differences $(\mathrm{P}<0.01)$ (One way ANOVA).

\section{Thiobarbituric acid reactive substances (TBARS)}

Rats in the ES group showed lower levels of brain TBARS (in nmol) than both the controls (mean \pm SD: $0.009 \pm 0.004$ vs. $0.025 \pm 0.004 ; \mathrm{P}<0.0001)$ and $\mathrm{S}$ group rats $(0.009 \pm 0.004$ vs. $0.037 \pm 0.003$; $\mathrm{P}<0.0001)$. Animals treated with the $\mathrm{E}$ also presented lower levels of brain TBARS compared with both the controls $(0.014 \pm 0.005$ vs. $0.025 \pm$ $0.004 ; \mathrm{P}=0.0014)$ and $\mathrm{S}$ group $(0.014 \pm 0.005$ vs. $0.037 \pm 0.003 ; \mathrm{P}<0.0001)$. Controls had lower levels of brain TBARS than the $\mathrm{S}$ group rats $(0.025 \pm 0.004$ vs. $0.037 \pm 0.003 ; \mathrm{P}<0.0001)$ (Fig. $4)$.

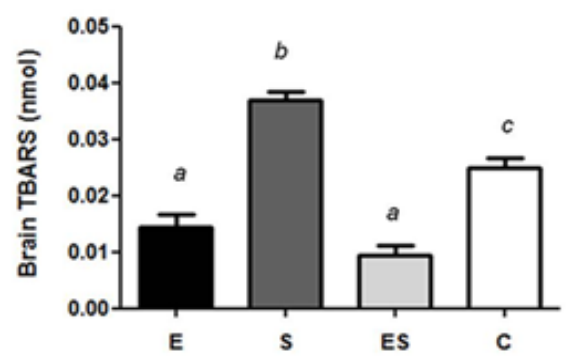

Figure 4 - Brain TBARS after treatments. Data are presented as the mean and std. deviation. Different letters represent significant differences $(\mathrm{P}<0.001)$ (One way ANOVA).

Rats treated with either E or ES showed a significant decrease in serum TBARS (in nmol) after the treatment (E: $0.025 \pm 0.002$ vs. $0.021 \pm$ 0.002 ; $\mathrm{P}<0.05 /$ ES: $0.027 \pm 0.002$ vs. $0.021 \pm$ $0.002 ; \mathrm{P}<0.001)$ as presented in Figure 5A. Other groups did not have significant decrease (S: 0.026 \pm 0.001 vs. $0.024 \pm 0.002 ; \mathrm{P}=0.35$ / C: $0.024 \pm$ 0.001 vs. $0.024 \pm 0.001 ; \mathrm{P}=0.39)$. Inter-treatment comparison showed that the magnitude of serum TBARS decrease was significantly higher in the
ES group than in both the controls $(-0.0061 \pm$ 0.0032 vs. $-0.0007 \pm 0.002 ; \mathrm{P}<0.01)$ and $\mathrm{S}$ group $(-0.0061 \pm 0.003$ vs. $-0.0012 \pm 0.002 \mathrm{~g} ; \mathrm{P}<0.01)$ (Fig. 5B).

\section{Cholesterol}

Serum cholesterol levels $(\mathrm{mg} / \mathrm{dL})$ increased significantly in both the controls $(43.8 \pm 8.0$ vs. $66.1 \pm 8.5 ; \mathrm{P}<0.0001)$ and $\mathrm{S}$ group rats $(50.8 \pm$ 6.2 vs. $62.2 \pm 11.9$; $\mathrm{P}<0.01)$ following the treatment. Rats treated with either E or ES did not have a significant increase in cholesterol (E: 48.4 \pm 6.7 vs. $56.5 \pm 6.4 ; \mathrm{P}=0.1 / \mathrm{ES}: 59.2 \pm 6.5$ vs. $63.5 \pm 3.5 ; \mathrm{P}=0.06$ ) (Fig. 6A). Inter-treatment comparisons (Fig. 6B) revealed that controls had a greater increase in serum cholesterol compared with the $\mathrm{E}(22.2 \pm 7.7$ vs. $8.0 \pm 7.7 ; \mathrm{P}<0.001), \mathrm{S}$ $(22.2 \pm 7.7$ vs. $11.4 \pm 8.0 ; \mathrm{P}<0.001)$ and $\mathrm{ES}(22.2$ \pm 7.7 vs. $5.3 \pm 5.8 ; \mathrm{P}<0.001)$ groups.

\section{Triglycerides}

Serum TG $(\mathrm{mg} / \mathrm{dl})$ decreased significantly in the E $(131.5 \pm 18.0$ vs. $57.42 \pm 8.9 ; \mathrm{P}<0.001), \mathrm{S}$ (126.29 \pm 14.2 vs. $99.26 \pm 19.6 ; \mathrm{P}<0.0001)$ and ES $(139.73 \pm 26.3$ vs. $77.00 \pm 18.3 ; \mathrm{P}<0.0001)$ groups after the treatment (Fig. 7A), whereas the control group demonstrated no change (126.91 \pm 31.7 vs. $113.37 \pm 17.9 ; \mathrm{P}=0.335$ ). Inter-treatment comparisons revealed that the magnitude of the decrease in TG was significantly higher in the $\mathrm{E}$ group than in both the controls (decrease in $\mathrm{mg} / \mathrm{dl}$ : $61.7 \pm 33.1$ vs. $13.5 \pm 27.7 ; \mathrm{P}<0.001)$ and $\mathrm{S}$ group $(61.7 \pm 33.1$ vs. $27.0 \pm 7.2 ; \mathrm{P}<0.001)$. The ES group had a significant decrease in TG when compared with the control $(62.7 \pm 16.5$ vs. $13.5 \pm$ $27.7 ; \mathrm{P}<0.001)$ and $\mathrm{S}$ group $(62.7 \pm 16.5$ vs. 27.0 $\pm 7.2 ; \mathrm{P}<0.001)$ (Fig. 7B). 
A

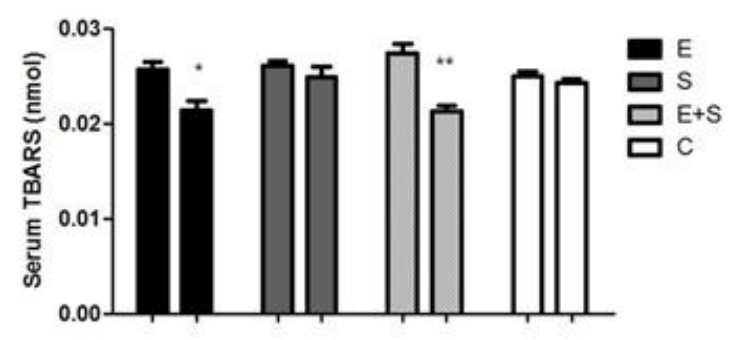

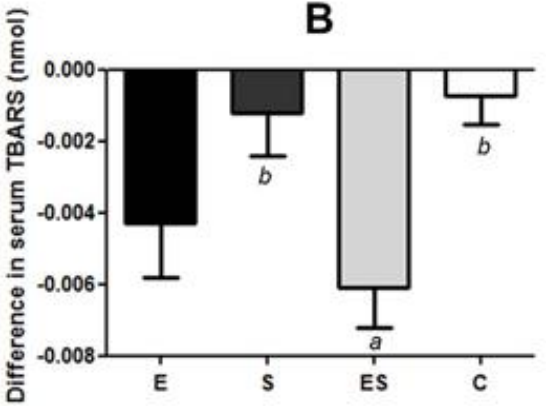

Figure 5 - Exercise alone and combined with $S$. platensis were both efficacious in reducing serum TBARS. (A) Serum TBARS before and after treatments. Data are presented as the mean and std. deviation. $* \mathrm{P}<0.05 ; * * \mathrm{P}<0.001$ (Student $\mathrm{t}$ tests followed by two way ANOVA). (B) Difference in serum TBARS after ten-week treatments. Data are presented as the mean and std. deviation. Different letters represent significant differences $(\mathrm{P}<0.01)$ (One way ANOVA).

A

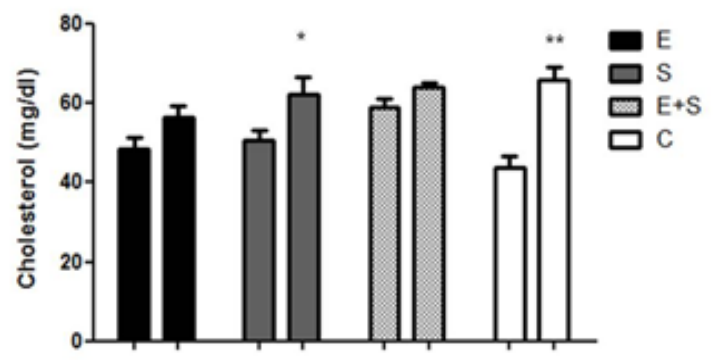

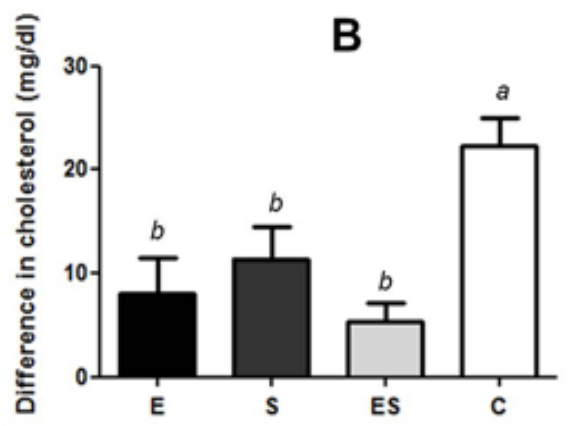

Figure 6 - The combination of exercise and S. platensis prevented an increase in serum cholesterol. (A) Cholesterol before and after treatments. Data are presented as the mean and std. deviation. $* \mathrm{P}<$ $0.01 ; * * \mathrm{P}<0.0001$ (Student $\mathrm{t}$ tests followed by two way ANOVA). (B) Difference in cholesterol after ten-week treatments. Data are presented as the mean and std. deviation. Different letters represent significant differences $(\mathrm{P}<0.001)$ (One way ANOVA).
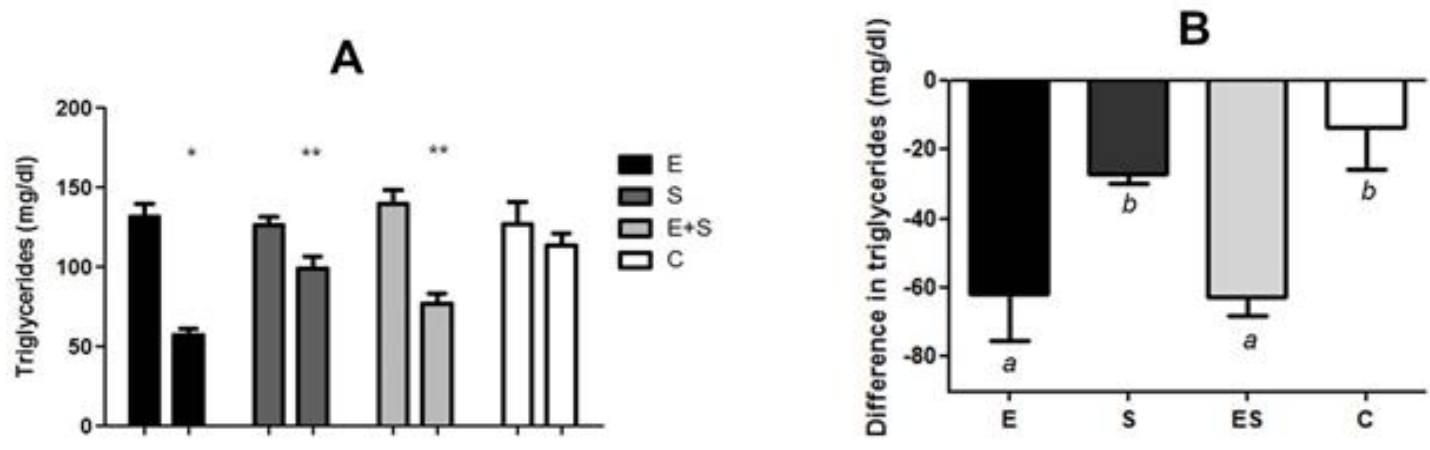

Figure 7 - Exercise, S. platensis and its combination decrease the triglycerides. (A) TG before and after treatments. Data are presented as the mean and std. deviation. $* \mathrm{P}<0.01$; **P $<0.0001$ (Student $\mathrm{t}$ tests followed by two way ANOVA). (B) Difference in TG after ten-week treatments. Data are presented as the mean and std. deviation. Different letters represent significant differences $(\mathrm{P}<0.001)$ (One way ANOVA). 


\section{DISCUSSION}

Oxidative stress and dyslipidemia have been the focus of intensive studies given their importance in the aging process and its relation with disease development (Vaziri et al. 2010; Hwang et al. 2011). Oxidative stress predominates in the different pathophysiology, with the emphasis in the cerebral injury (Gomez-Pinilla 2011; Macedo et al. 2014). A greater susceptibility of the brain to oxidative stress is supported by several evidences. The brain accounts for only $2 \%$ of the body weight, but it consumes about $20 \%$ of the body oxygen, which increases the mitochondrial formation of ROS. The brain contains relatively high concentrations of readily peroxidizable lipids, such as polyunsaturated fatty acids, representing one third of the brain fatty acids (Hwang et al. 2011). As a result, lipid peroxidation is one of the major consequences of the free radical mediated injury to the brain (Hwang et al. 2011; Zheng et al. 2013).

Different investigations have shown significant results in the use of Spirulina platensis against oxidative stress and dyslipidemias (BermejoBescós et al. 2008; Hwang et al. 2011; Farooq et al. 2014). Based on this, studies were conducted to assess the oxidative stress and lipid profiles in the rats treated with $S$. platensis, moderate exercise, or both. For the assessment of oxidative stress, brain and serum TBARS were measured, which was a marker of lipid peroxidation, resulting from the process of oxidative stress (Gustav-Rothenberg et al. 2010; Potter et al. 2011). Lipid profiles were evaluated by measuring cholesterol and TG in the serum. The main findings of this study were as follows: (1) rats had lower levels of brain TBARS when treated with exercise, particularly in association with $S$. platensis; (2) exercise alone and exercise combined with $S$. platensis both reduced serum TBARS; and (3) compared with the controls, both exercise alone and exercise plus $S$. platensis prevented the increase in cholesterol levels and diminished serum TG.

The present results demonstrated that the rats treated with exercise had lower levels of brain TBARS, particularly when exercise was combined with $S$. platensis. This latter regimen also showed benefits in reducing serum TBARS. In the clinical context, these findings indicated that exercise might be useful to prevent the conditions related to oxidative stress such as cardiovascular and neurodegenerative diseases. Furthermore, the combination of exercise and $S$. platensis might potentiate such action. In humans, a study evaluating the acute antioxidant response to exercise plus $S$. platensis found that the supplementation of $S$. platensis significantly decreased carbohydrate oxidation rate and increased glutathione levels in comparison with placebo (Kalafati et al. 2010). These results were in agreement with the present findings, which observed an improvement in lipid peroxidation in serum in the rats treated with exercise and $S$. platensis. Zheng et al. (2013) reported decreased lipid peroxidation in the hippocampus and cortex with the use of $S$. platensis in the rats at a dosage of $50 \mathrm{mg} / \mathrm{Kg}$ per day. In the present study, the combination of exercise and S. platensis prevented an increase in serum cholesterol after short-term treatment, compared with the controls. Most studies in the literature observed a decrease in cholesterol after exercise alone or exercise combined with nutritional supplements, such as vitamin E and carnitine (Quiles et al. 2003; Kim et al. 2004).

Meilhac et al. (2001) found that exercise combined with vitamin $E$ prevented the increase in cholesterol in mice treated with a hypercholesterolemic diet; mice treated with normal diet showed an increase in cholesterol levels after exercise compared with sedentary animals. Nakaya et al. (1988) reported that individuals with higher levels of serum cholesterol received greater benefits in reducing cholesterol after treatment with $S$. platensis. According to Ramamoorthy and Premakumari, (1996), the greater the amount of S. platensis that was offered, the greater was the reduction in cholesterol levels. These data explained the present results observed in the S. platensis group, which did not present benefits because the animals were not hypercholesterolemic. In addition, the $S$. platensis dose used in the present study was relatively low compared with that used in other studies (Kim and Park 2003; Khan et al. 2005). The serum TG was reduced after all the interventions, except in the control group. The most pronounced decrease was observed in the rats treated with exercise and exercise plus $S$. platensis. A study with overweight humans demonstrated that exercise associated with supplementation with whey protein, which has antioxidant properties, resulted in a significant decrease in TG in the experimental groups (exercise and exercise plus supplementation) and an increase in the total antioxidant capacity that 
was not observed in the control group (Sheikholeslami and Ahmadi 2012). However, the effects of $S$. platensis on TG have been controversial in other studies. Cheong et al. found a decrease in TG after the treatment with $S$. platensis in the rabbits with increased levels of serum lipids (Cheong et al. 2010).

These benefits were potentiated when S. platensis was combined with exercise. In this context, there was agreement with Lu et al. (2006), who aimed to assess the effects of Spirulina supplementation on preventing skeletal muscle damage on untrained human beings. The results showed that plasma concentrations of malondialdehyde (MDA) were significantly decreased after supplementation with Spirulina $(\mathrm{P}<0.05)$. These results suggested that the ingestion of $S$. platensis showed preventive effect of the skeletal muscle damage and that probably led to postponement of the time of exhaustion during the all-out exercise. Kalafati et al. (2010) reported the benefits of S. platensis combined with physical exercise. The supplementation with Spirulina induced a significant increase in exercise performance, fat oxidation, and GSH concentration and attenuated the exercise-induced increase in lipid peroxidation. Pinilla Gomez (2011) showed the importance of physical exercise and dietary supplementation with functional substances with a view to mitigating damage and preventive health care with emphasis on brain health. Several other studied have shown the importance of the choice of preventive strategies for health. The use of $S$. platensis cyanobacteria has been shown with significant attenuation capacity of free radicals, preventing and/or avoiding the installation of different pathologies (Bermejo-Bescós et al. 2008; Bertolin et al. 2009; Pabon et al. 2012; Farooq et al. 2014; Yogianti et al. 2014). Results of these studies and present results matched on the profiles of oxidative stress and lipid levels in mice with the use of therapies moderate exercise and S. platensis.

\section{CONCLUSION}

In conclusion, the use of $S$. platensis and moderate exercise on showed decreased levels of TBARS, a marker of oxidative stress in the brain and serum. These benefits were potentiated when S. platensis was combined with exercise. This combination also prevented an increase in serum cholesterol and decreased TG levels. Therefore, moderate exercise and $S$. platensis might be useful in treating the cardiovascular, neurodegenerative and other diseases related to aging. Further studies are needed to confirm the benefits of these interventions in humans.

\section{ACKNOWLEDGEMENTS}

The authors would like to thank the Instituto de Ciências Biológicas - UPF - which provided the location and facilities to perform the experimental work. This work was supported by grants from $\mathrm{CNPq}$ and PPGEH.

\section{REFERENCES}

Adibhatla RM, Hatcher JF. Altered lipid metabolism in brain injury and disorders. Subcell Biochem. 2008; 49:241-268.

Akao Y, Ebihara T, Masuda H, Saeki Y, Akazawa T, Seya T, et al. Enhancement of antitumor natural killer cell activation by orally administered Spirulina extract in mice. Cancer Sc. 2009; 100:1494-1501.

ANVISA - Agência Nacional de Vigilância Sanitária. VII Lista dos novos ingredientes aprovados. Disponível em: www.anvisa.gov.br. ANVISA, 2009.

Babusikova E, Hatok J, Dobrota D, Kaplan P. Agerelated oxidative modifications of proteins and lipids in rat brain. Neurochem Res. 2007; 32:1351-1356.

Bermejo-Bescós P, Piñero-Estrada H, Fresno A. Neuroprotection by Spirulina platensis protean extract and phycocyanin against iron-induced toxicity in SH-SY5Y neuroblastoma cells. Toxicol in Vitro. 2008; 22:1496-1502.

Bertolin TE, Pilatti D, Giacomini ACVV, Bavaresco K, Colla LM, Costa JAV. Effect of microalga Spirulina platensis (Arthrospira platensis) on hippocampus lipoperoxidation and lipid profile in rats with induced hypercholesterolemia. Braz Arch Biol Technol. 2009; 52:1253-1259.

Blagosklonny MV. Why human lifespan is rapidly increasing: solving "longevity riddle" with "revealedslow-aging" hypothesis. Aging. (Albany NY). 2010; 2:177-182.

Cakir B, Kasimay O, Kolgazi M, Ersoy Y, Ercan F, Yeğen BC. Stress-induced multiple organ damage in rats is ameliorated by the antioxidant and anxiolytic effects of regular exercise. Cell Biochem Funct. 2010; 28:469-479.

Cheong SH, Kim MY, Sok DE, Hwang S-Y, Kim JH, Kim MR, et al. Spirulina prevents atherosclerosis by reducing hypercholesterolemia in rabbits fed a highcholesterol diet. J Nutr Sci Vitaminol. (Tokyo). 2010; 56:34-40. 
Farooq SM, Boppana NB, Asokan D, Sekaran SD, Shankar EM, Ebrahim AS, et al. C-Phycocyanin Confers protection against oxalate-mediated oxidative stress and mitochondrial dysfunctions in MDCK cells. Plos One. 2014; 9:1-9.

FIOCRUZ - Fundação Oswaldo Cruz. Manual para técnicos em animais de laboratório: capacitação de pessoal de níveis elementar e médio em biotérios CPNEMB. Rio de Janeiro: Fundação Oswaldo Cruz/CICT. 1994.

Gamba P, Testa G, Gargiulo S, Staurenghi E, Poli G, Leonarduzzi G. Oxidized cholesterol as the driving force behind the development of Alzheimer's disease. Aging Neuroscience. 2015; 7:1-21.|

Gomez-Cabrera MC, Domenech E, Vina J. Moderate exercise is an antioxidant: upregulation of antioxidant genes by training. Free Radic Biol Med. 2008; 44:126-131.

Gomez-Pinilla F. The combined effects of exercise and foods in preventing neurological and cognitive disorders. Prev Med. 2011; 1:75-80.

Gustaw-Rothenberg K, Kowalczuk K, StryjeckaZimmer M. Lipids' peroxidation markers in Alzheimer's disease and vascular dementia. Geriatr Gerontol Int. 2010; 10:161-166.

Hare DJ, Arora M, Jenkins NL, Finkelstein DI, Doble PA, Bush AI. Is early-life iron exposure critical in neurodegeneration? Nature Reviews - Neurol. 2015; $1-9$.

Hwang JH, Lee T, Jeng KC, Wang MF, Hou RCW, Chan YC, et al. Spirulina prevents memory dysfunction, reduces oxidative stress damage and augments antioxidant activity in senescence accelerated mice. J Nutr Sci Vitaminol. 2011; 57:186191.

Kalafati M, Jamurtas AZ, Nikolaidis MG, Paschalis V, Theodorou AA, Kouretas D, et al. Ergogenic and antioxidant effects of Spirulina supplementation in humans. Med Sci Sports Exerc. 2010; 42:142-151.

Khan Z, Bhadouria P, Bisen PS. Nutritional and therapeutic potential of Spirulina. Curr Pharm Biotechnol. 2005; 6:373-379.

Kim E, Park H, Cha YS. Exercise training and supplementation with carnitine and antioxidants increases carnitine stores, triglyceride utilization, and endurance in exercising rats. J Nutr Sci Vitaminol (Tokyo). 2004; 50:335-343.

Kim WY, Park YC. The effect of Spirulina on lipid metabolism, antioxidant capacity and immune function in Korean Erlerlies. Korean J Nutr. 2003; 36:287-297.

Macedo D, Gordon LT, McDougall M, Miranda HV, Stewart D, Santos, CN, et al. (Poly)phenols protect from $\alpha$-synuclein toxicity by reducing oxidative stress and promoting autophagy. Human Mol Genetics. 2014; $1-16$.
Meilhac O, Ramachandran S, Chiang K, Santanan N, Parthasarathy S. Role of arterial wall antioxidant defense in beneficial effects of exercise on atherosclerosis in mice. Arterioscler Thromb Vasc Biol. 2001; 21:1681-1688.

Nakaya N, Homa Y, Goto Y. Cholesterol lowering effect of Spirulina. Nutr Repint. 1988; 37:1329-1337.

Navarro A, Boveris A. Brain mitochondrial dysfunction in aging, neurodegeneration, and Parkinson's disease. Front Aging Neurosci. 2010; 2:34-41.

Negre-Salvayre A, Auge N, Ayala V, Basaga H, Boada J, Zarkovic N, et al. Pathological aspects of lipid peroxidation. Free Radic Res. 2010; 44:1125-1171.

Onat A, Can G, Yuksel H. Dysfunction of high-density lipoprotein and its apolipoproteins: New mechanisms underlying cardiometabolic risk in the population at large. Turk Kardiyol Dern Ars. 2012; 40:368-385.

Pabon MM, Jernberg JN, Morganti J, Contreras J, Hudson CE, Bickford PC, et al. A Spirulina-enhanced diet provides neuroprotection in an $\alpha$-Synuclein model of Parkinson's Disease. Plos One. 2012; 7:1-7.

Potter TM, Neun BW, Stern ST. Assay to detect lipid peroxidation upon exposure to nanoparticles. Methods Mol Biol. 2011; 697:181-189.

Quiles JL, Huertas JR, Ochoa JJ, Battino M, Mattaix J, Mañas M. Dietary fat (virgin olive oil or sunflower oil) and physical training interactions on blood lipids in the rat. Nutrition. 2003; 19:363-368.

Quirós PM, Langer T, Otín CL. New roles for mitochondrial proteases in health, ageing and disease. Nature Reviws, Molecular Cell Biology. 2015; 16:345-359.

Ramamoorthy A, Premakumari S. Effect of supplementation of Spirulina on hypercholesterolemic patients. J Food Sci Technol. 1996; 33:124-128.

Sainz N, Rodriguez A, Catalan V, Becerril S, Ramírez B, Frühbeck G, et al. Leptin administration downregulates the increased expression levels of genes related to oxidative stress and inflammation in the skeletal muscle of ob/ob mice. Mediators Inflamm. 2010; 2010:784.

Scott CT, DeFrancesco L. Selling long life. Nature Biotechnol. 2015; 33:31-40.

Sheikholeslami VD, Ahmadi Kani GF. Changes in antioxidant status and cardiovascular risk factors of overweight young men after six weeks supplementation of whey protein isolate and resistance training. Appetite. 2012; 59:673-678.

Steels EL, Learmonth, RP, Watson K. Stress tolerance and membrane lipid unsaturation in Saccharomyces cerevisiae grown aerobically or anaerobically. Microbiol. 1994; 140:569-576.

Ungvari Z, Kaley G, Cabo R, Sonntag WE, Sciszar A. Mechanisms of vascular aging: new perspectives. $J$ Gerontol A Biol Sci Med Sci. 2010; 65:1028-1041.

Vaupel JW. Biodemography of human ageing. Nature. 2010; 464:536-542. 
Vaziri ND, Navab M, Fogelman AM. HDL metabolism and activity in chronic kidney disease. Nature Reviews Nephrology. 2010; 6:287-296.

Venditti P, Di MS. Effect of training on antioxidant capacity, tissue damage, and endurance of adult male rats. Int J Sports Med. 1997; 18:497-502.

Vina J, Gimeno A, Sastre J, Desco C, Asensi M, Repine $\mathrm{JE}$, et al. Mechanism of free radical production in exhaustive exercise in humans and rats; role of xanthine oxidase and protection by allopurinol. IUBMB Life. 2000; 49:539-544.

Wang X, Michaelis EK. Selective neuronal vulnerability to oxidative stress in the brain. Front Aging Neurosci. 2010; 2:12-21.
Yogianti F, Kunisada M, Nakano E, Ono R, Sakumi K, Nishigori $\mathrm{C}$, et al. Inhibitory Effects of Dietary Spirulina platensis onUVB-Induced Skin Inflammatory Responses and Carcinogenesis. $J$ Investigative Dermatol. 2014; 134:2610-2619.

Zheng JL, Inoguchi T, Sasaki S, Maeda Y, McCarty MF, Takayanagi R, et al. Phycocyanin and phycocyanobilin from Spirulina platensis protect against diabetic nephropathy by inhibiting oxidative stress. Am J Physiol Regul Integr Comp Physiol. 2013; 304:110-120. 